\title{
Nosocomial Infections with IMP-19-Producing Pseudomonas aeruginosa Linked to Contaminated Sinks, France
}

\section{Lucie Amoureux, Karena Riedweg, Angélique Chapuis, Julien Bador, Eliane Siebor, André Péchinot, Marie-Lorraine Chrétien, Claire de Curraize, Catherine Neuwirth}

We isolated IMP-19-producing Pseudomonas aeruginosa from 7 patients with nosocomial infections linked to contaminated sinks in France. We showed that $b / a_{\text {IMP-19 }}$ was located on various class 1 integrons among 8 species of gram-negative bacilli detected in sinks: $P$. aeruginosa, Achromobacter xylosoxidans, $A$. aegrifaciens, $P$. putida, Stenotrophomonas maltophilia, P. mendocina, Comamonas testosteroni, and Sphingomonas sp.

A cquired metallo- $\beta$-lactamases (MBLs) belong to the families IMP, VIM, NDM, SPM, GIM, SIM, DIM, KHM, TMB, FIM, and AIM (1). IMP and VIM are the most common families. MBLs have been reported worldwide among Pseudomonas aeruginosa isolates (2). Therapeutic options for infected patients are severely limited because isolates are resistant to many classes of antimicrobial drugs. Genes for MBLs are found mostly in class 1 integrons, which carry additional drug resistance genes. To date, 33 of the 51 known IMP variants have been detected in P. aeruginosa; there has been only 1 report of an IMP-19 producer (3). This MBL is widespread among Acinetobacter spp. in Japan and has also been reported in Achromobacter xylosoxidans $(4,5)$.

During 2009-2016, infections with IMP-19-producing $P$. aeruginosa isolates were detected in 7 patients in the Hematology Department of University Hospital François Mitterrand, a 1,600-bed hospital in Dijon, France. We describe these infections and report results of environmental investigations.

\section{The Study}

The hematology department of the hospital contains a 15-bed conventional unit and a 9-bed protective isolation unit. At the entrances of rooms in the conventional unit, there is a hand hygiene sink (for staff and visitors) and a bathroom in a separate area (shower stall, sink, and toilets). In the protective isolation unit, air is filtered through

Author affiliation: University Hospital François Mitterrand,

Dijon, France

DOI: http://dx.doi.org/10.3201/eid2302.160649 a laminar flow system, and a sink and toilets are located next to each bed (distance $1.5 \mathrm{~m}$ ). The ceramic sinks have no counter space, and drains are made of stainless steel. All faucets in the department are hand-operated and provided with antibacterial filters $(0.22 \mu \mathrm{m})$. Surfaces are cleaned daily (once in the conventional unit and twice in the protective isolation unit) with a solution containing quaternary ammonium compounds $(0.25 \%$ didecyldimethylammonium chloride).

During 2009-2016, a total of 7 patients (P1-P7) in the department were infected or colonized by IMP-19-producing $P$. aeruginos $a$, which were isolated from blood samples ( 2 patients), urine samples ( 2 patients), throat swab samples (2 patients), and a central venous catheter (1 patient). All patients underwent throat, urine, and feces sampling at admission and were free of $P$. aeruginosa, thus indicating nosocomial acquisition. All isolates were resistant to ceftazidime, imipenem, meropenem, doripenem, ciprofloxacin, and most aminoglycosides; 4 isolates were susceptible to piperacillin and 3 to amikacin.

We conducted an environmental investigation in the hospital (Figure 1, https://wwwnc.cdc.gov/EID/article/ 23/2/16-0649-F1.htm). More than 100 environmental samples were obtained when no patients were colonized (except for samples collected in room 32 a few hours after patient $\mathrm{P} 7$ had been transferred to an intensive care unit). Water samples were collected from different faucets (nursing room, medication preparation rooms, and rooms of some patients). First-catch lukewarm water (500 $\mathrm{mL}$ ) was collected in sterile bottles containing $20 \mathrm{mg} / \mathrm{L}$ sodium thiosulfate and concentrated by filtration $(0.45$ $\mu \mathrm{m}$ membrane filters). All sinks and shower drains were sampled by rotating a cotton swab inserted through the drain. Toilets were sampled with swabs inserted under the rim of the toilet bowl.

We plated samples from filters (for water) and swab specimens (from sinks) on Drigalski medium containing ceftazidime $(32 \mathrm{mg} / \mathrm{L})$. When a positive culture was observed after 48 hours of incubation, a PCR specific for $b l a_{\mathrm{IMP}-19}$ was performed for the culture mixture. For samples with a positive PCR result, we then plated a dilution of the culture mixture on Drigalski medium containing ceftazidime $(32 \mathrm{mg} / \mathrm{L})$ and imipenem $(16 \mathrm{mg} / \mathrm{L})$ to obtain isolated colonies, which we further subjected to identification and confirmation of IMP-19 production. 
Many resistant organisms were detected in these environmental samples. We used mass spectrometry and $n r d A$ gene sequencing to identify for Achromobacter isolates (6). $b l a_{\mathrm{IMP}-19}$ and integrons were detected as described $(7,8)$. We used pulsed-field gel electrophoresis after $\mathrm{XbaI}$ digestion to genotype $P$. aeruginosa isolates ( 9 ). Pulsotypes were compared by calculating the Dice correlation coefficient with DendroUPGMA software (http://genomes.urv.cat/UPGMA/).

The 7 clinical isolates belonged to 3 distinct genotypes A, B, and C (Table; Figure 2). We detected environmental IMP-19-producing isolates belonging to 8 species of gramnegative nonfermenting bacilli: $P$. aeruginosa, Achromobacter xylosoxidans, A. aegrifaciens, P. putida, Stenotrophomonas maltophilia, P. mendocina, Comamonas testosteroni, and Sphingomonas sp. Of the 7 environmental isolates of $P$. aeruginosa we identified, 6 belonged to the same genotype as clinical isolates (genotype A).

The bla $_{\mathrm{IMP}-19}$ gene was located in various integrons, mainly on a sul-type class 1 integron and Tn402-like class 1 integron. In these integrons, $b l a_{\mathrm{IMP}-19}$ was associated with different gene cassettes, including $a a c\left(6^{\prime}\right)-I b$, aadA13, aadB, or fused $q a c G-a a c\left(6^{\prime}\right)-I b$ (Figure 3). Few isolates had several copies of $b a_{\mathrm{IMP}-19}$ located on integrons of different structures (Table).

\section{Conclusions}

The incidence of MBL producers among imipenemresistant $P$. aeruginosa in France is low compared with incidences for other countries $(2,10)$. Reports of outbreaks are scarce and usually involve VIM producers $(11,12)$. Therefore, detection of IMP-19 producers in our hospital was unusual. The long intervals without cases, the absence of any overlap between cases, and genotypic diversity of clinical isolates did not suggest a single common source of infection. These findings prompted us to conduct environmental investigations.

IMP-19 producers were detected in 9 of 15 rooms in the conventional unit and 2 of 9 rooms in the protective isolation unit. These producers were $P$. aeruginosa and a wide variety of gram-negative nonfermenting bacilli. Most of these producers have little clinical relevance, but they are silent reservoirs for dissemination of $b a_{\mathrm{IMP}-19}$ to major pathogens. The role of these environmental bacterial species in the spread of MBL suggested in previous studies $(13,14)$ is confirmed by our findings.

The diversity of species found and genetic structures involved with $b l a_{\mathrm{IMP}-19}$ indicated that the environmental contamination occurred a long time ago. One isolate of IMP-19-producing Aeromonas caviae was found in a patient in the same building in 2006 (7). This phenomenon is probably endemic to our hospital, in which sink drains are not accessible for removal of biofilms without complete dismantling (inappropriate sink design).

Transfer of pathogens from sinks to patients might occur in several ways. Water from faucets is directed

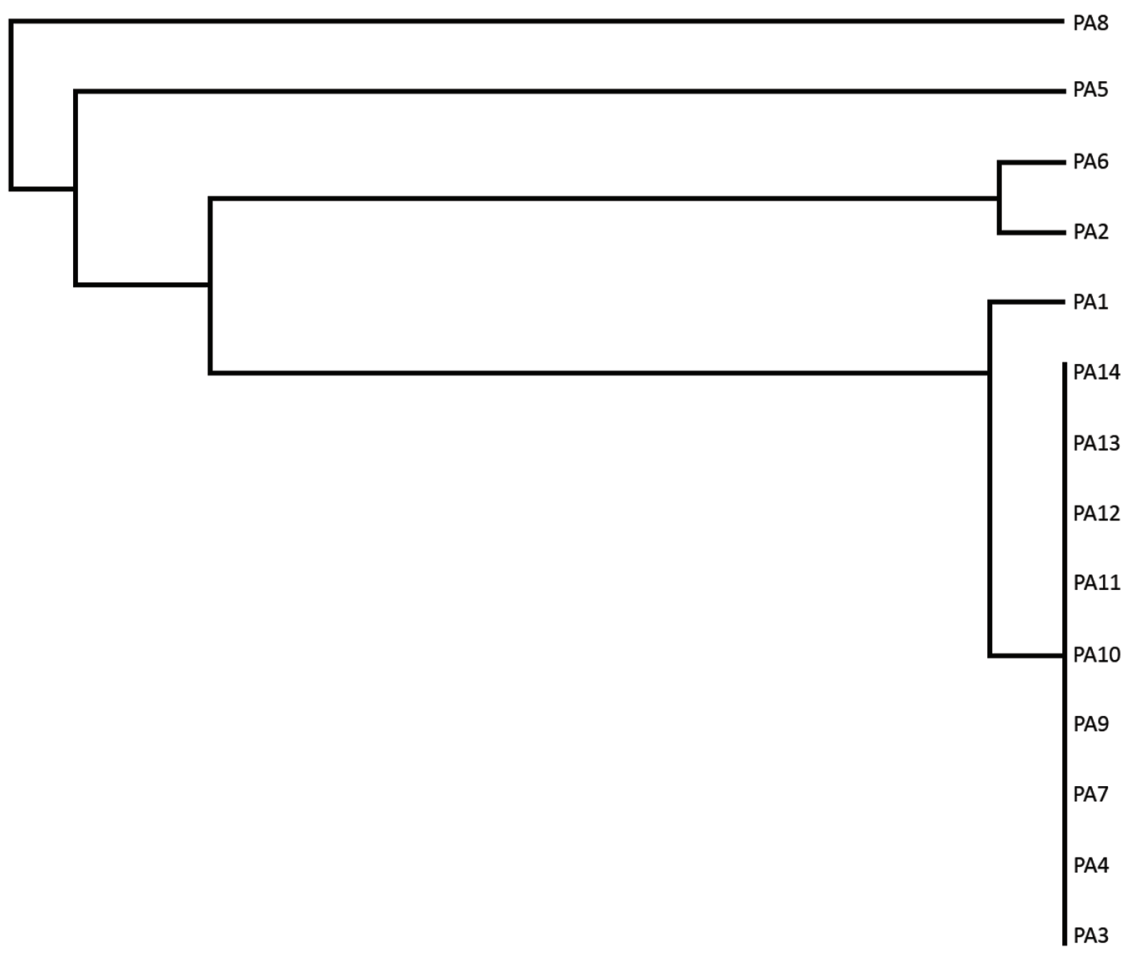

Figure 2. Unweighted pair group method with arithmetic mean cluster analysis of Xbal-generated pulsotypes constructed with Dice coefficients for the 7 clinical isolates and the 7 environmental isolates of IMP-19-producing Pseudomonas aeruginosa (PA) linked to contaminated sinks, France. Isolates are indicated on dendrogram branches. The Dice coefficient scale is indicated at the bottom of the dendrogram.

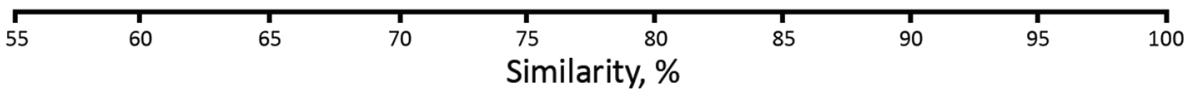




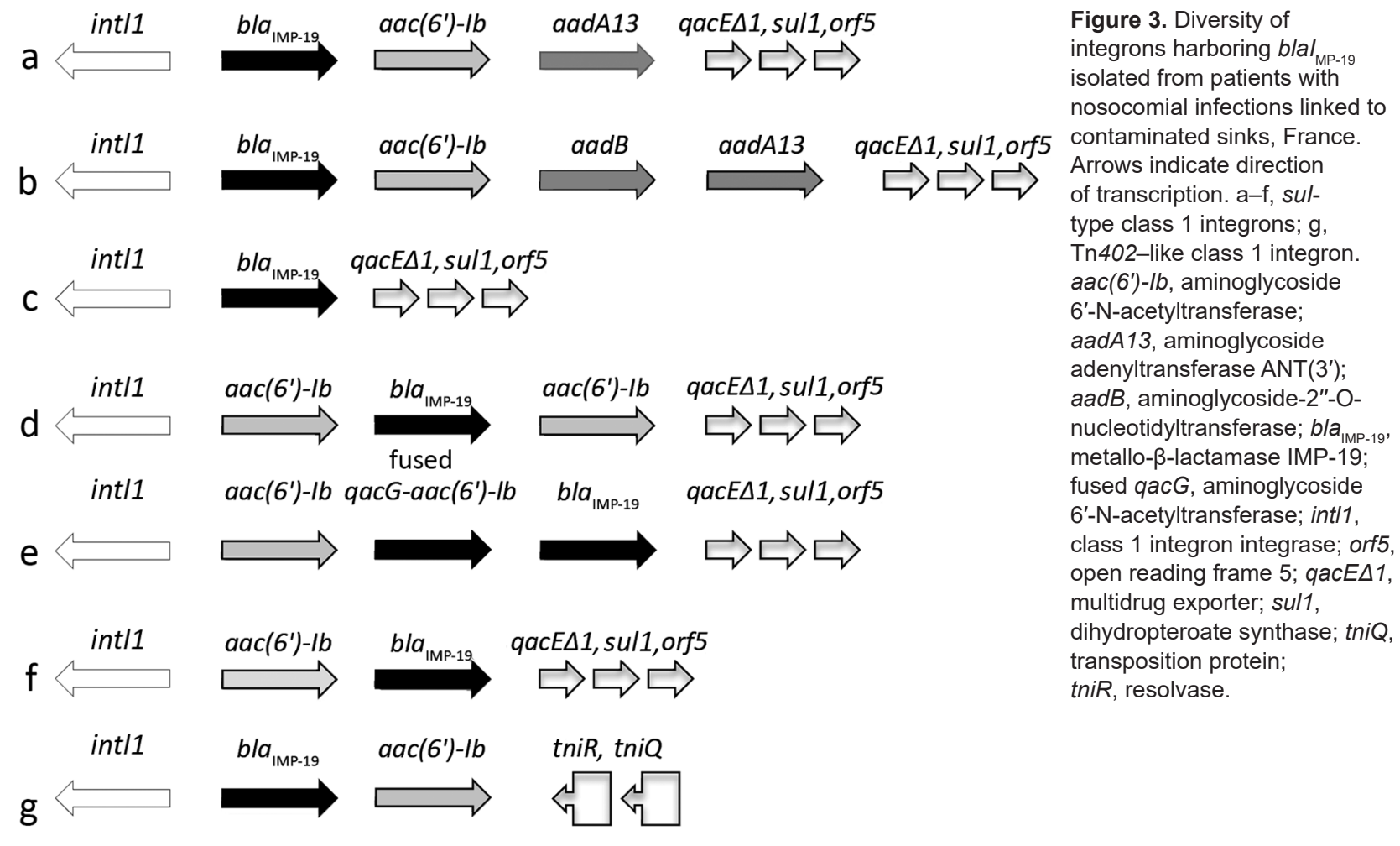

straight into the drain, resulting in splashing that can lead to contamination of an area $\leq 1 \mathrm{~m}$ from the sink (15). Therefore, patients can be contaminated when they brush their teeth, wash their hands, or take a shower. Healthcare personnel are also at risk for hand contamination, which might lead to transfer of pathogens to patients during care.

All patients had $\geq 1$ stay in rooms that were positive for IMP-19-producing organisms. After patient P7 died of sepsis, all drains in the ward were changed. However, this

\begin{tabular}{|c|c|c|c|c|}
\hline Isolate & Origin (date) & Site & PFGE profile & Integron \\
\hline Pseudomonas aeruginosa PA1 & Patient P1 (2009 Feb) & Urine & $A$ & $\mathrm{D}$ \\
\hline$P$. aeruginosa PA2 & Patient P2 (2009 Apr) & Blood & $\mathrm{B}$ & A \\
\hline$P$. aeruginosa $\mathrm{PA} 3$ & Patient P3 (2009 Jun) & Throat & A & D \\
\hline P. aeruginosa PA4 & Patient P4 (2013 Oct) & Urine & A & $\mathrm{D}$ \\
\hline P. aeruginosa PA5 & Patient P5 (2015 Oct) & Central catheter & C & $\mathrm{F}$ \\
\hline P. aeruginosa PA6 & Patient P6 (2015 Dec) & Throat & B & A \\
\hline P. aeruginosa PA7 & Patient P7 (2016 Jul) & Blood & A & ND \\
\hline$P$. aeruginosa PA8 & Room 10 (protective unit) & Sink & Unrelated & G \\
\hline P. aeruginosa PA9 & Room 40 & Shower drain & A & A \\
\hline P. aeruginosa PA10 & Room 40 & Shower drain & A & $E, F$ \\
\hline P. aeruginosa PA11 & Room 40 & Sink & A & $\mathrm{B}, \mathrm{C}$ \\
\hline P. aeruginosa PA12 & Room 46 & Shower drain & A & D \\
\hline P. aeruginosa PA13 & Room 32 & Sink & A & ND \\
\hline P. aeruginosa PA14 & Room 32 & Toilet bowl & A & ND \\
\hline Achromobacter xylosoxidans & Room 48 & Sink & ND & $\mathrm{F}$ \\
\hline A. aegrifaciens & Room 32 & Toilet bowl & ND & $E, F$ \\
\hline A. aegrifaciens & Room 37 & Shower drain & ND & $\mathrm{E}, \mathrm{F}$ \\
\hline P. putida & Room 32 & Toilet bowl & ND & $\mathrm{E}, \mathrm{F}$ \\
\hline$P$. putida & Room 4 & Shower drain & ND & $\mathrm{E}, \mathrm{F}$ \\
\hline$P$. putida & Room 64 & Shower drain & ND & $\mathrm{G}$ \\
\hline$P$. putida & Room 65 & Toilet bowl & ND & $\mathrm{C}$ \\
\hline Sphingomonas sp. & Room 12 (protective unit) & Sink & ND & ND \\
\hline Comamonas testosteroni & Room 46 & Sink & ND & ND \\
\hline P. mendocina & Room 40 & Shower drain & ND & $E, F$ \\
\hline Stenotrophomonas maltophilia & Room 44 & Sink & ND & ND \\
\hline
\end{tabular}

${ }^{*} \mathrm{ND}$, not determined; PFGE, pulsed-field gel electrophoresis. 
measure did not eradicate biofilms found in the plumbing system. Because the building tested was 16 years old, it has been decided to completely rebuild the ward in early 2017 , paying special attention to water distribution and discharge systems to minimize hospital-acquired infections. In conclusion, our findings might help other hospitals to identify potential reservoirs of carbapenemase-producing bacteria and lead to implementation of rapid control measures to contain outbreaks.

\section{Acknowledgments}

We thank N. Sixt for performing water analysis and P. Bastable for correcting and editing the manuscript.

This study was supported by the Association Dijonnaise des Bactériologistes.

Dr. Amoureux is research scientist in the Bacteriology

Department, University Hospital François Mitterrand, Dijon, France. Her research interests are epidemiology and resistance of nonfermenting gram-negative bacilli, specifically Achromobacter spp., in immunocompromised patients and those with cystic fibrosis.

\section{References}

1. Zhao WH, Hu ZQ. Acquired metallo- $\beta$-lactamases and their genetic association with class 1 integrons and ISCR elements in gram-negative bacteria. Future Microbiol. 2015;10:873-87. http://dx.doi.org/10.2217/fmb.15.18

2. Cornaglia G, Giamarellou H, Rossolini GM. Metallo- $\beta$-lactamases: a last frontier for $\beta$-lactams? Lancet Infect Dis. 2011;11:381-93. http://dx.doi.org/10.1016/S1473-3099(11)70056-1

3. Pollini S, Antonelli A, Venturelli C, Maradei S, Veggetti A, Bracco S, et al. Acquisition of plasmid-borne $b l a_{\mathrm{IMP}-19}$ gene by a VIM-1-positive Pseudomonas aeruginosa of the sequence type 235 epidemic lineage. J Antimicrob Chemother. 2013;68:722-4. http://dx.doi.org/10.1093/jac/dks440

4. Yamamoto M, Nagao M, Matsumura Y, Hotta G, Matsushima A, Ito $\mathrm{Y}$, et al. Regional dissemination of Acinetobacter species harbouring metallo- $\beta$-lactamase genes in Japan. Clin Microbiol Infect. 2013;19:729-36. http://dx.doi.org/10.1111/1469-0691.12013

5. Yamamoto M, Nagao M, Hotta G, Matsumura Y, Matsushima A, Ito $\mathrm{Y}$, et al. Molecular characterization of IMP-type metallo- $\beta$ lactamases among multidrug-resistant Achromobacter xylosoxidans. J Antimicrob Chemother. 2012;67:2110-3. http://dx.doi.org/10.1093/jac/dks179
6. Spilker T, Vandamme P, Lipuma JJ. Identification and distribution of Achromobacter species in cystic fibrosis. J Cyst Fibros. 2013;12:298-301. http://dx.doi.org/10.1016/j.jcf.2012.10.002

7. Neuwirth C, Siebor E, Robin F, Bonnet R. First occurrence of an IMP metallo-beta-lactamase in Aeromonas caviae: IMP-19 in an isolate from France. Antimicrob Agents Chemother. 2007;51: 4486-8. http://dx.doi.org/10.1128/AAC.01462-06

8. Betteridge T, Partridge SR, Iredell JR, Stokes HW. Genetic context and structural diversity of class 1 integrons from human commensal bacteria in a hospital intensive care unit. Antimicrob Agents Chemother. 2011;55:3939-43. http://dx.doi.org/10.1128/ AAC.01831-10

9. Tsakris A, Tassios PT, Polydorou F, Papa A, Malaka E, Antoniadis A, et al. Infrequent detection of acquired metallobeta-lactamases among carbapenem-resistant Pseudomonas isolates in a Greek hospital. Clin Microbiol Infect. 2003;9:846-51. http://dx.doi.org/10.1046/j.1469-0691.2003.00642.x

10. Fournier D, Richardot C, Müller E, Robert-Nicoud M, Llanes C, Plésiat P, et al. Complexity of resistance mechanisms to imipenem in intensive care unit strains of Pseudomonas aeruginosa. J Antimicrob Chemother. 2013;68:177280. http://dx.doi.org/10.1093/jac/dkt098

11. Ambrogi V, Cavalié L, Mantion B, Ghiglia MJ, Cointault $\mathrm{O}$, Dubois D, et al. Transmission of metallo- $\beta$-lactamase-producing Pseudomonas aeruginosa in a nephrology-transplant intensive care unit with potential link to the environment. J Hosp Infect. 2016;92:27-9. http://dx.doi.org/10.1016/j.jhin.2015.09.007

12. Corvec S, Poirel L, Espaze E, Giraudeau C, Drugeon H, Nordmann P. Long-term evolution of a nosocomial outbreak of Pseudomonas aeruginosa producing VIM-2 metallo-enzyme. J Hosp Infect. 2008;68:73-82. http://dx.doi.org/10.1016/j. jhin.2007.10.016

13. Bogaerts P, Bouchahrouf W, Lissoir B, Denis O, Glupczynski Y. IMP-13-producing Pseudomonas monteilii recovered in a hospital environment. J Antimicrob Chemother. 2011;66:2434-5. http://dx.doi.org/10.1093/jac/dkr294

14. Gilarranz R, Juan C, Castillo-Vera J, Chamizo FJ, Artiles F, Álamo I, et al. First detection in Europe of the metallo- $\beta$-lactamase IMP-15 in clinical strains of Pseudomonas putida and Pseudomonas aeruginosa. Clin Microbiol Infect. 2013;19:E424-7. http://dx.doi.org/10.1111/1469-0691.12248

15. Hota S, Hirji Z, Stockton K, Lemieux C, Dedier H, Wolfaardt G, et al. Outbreak of multidrug-resistant Pseudomonas aeruginosa colonization and infection secondary to imperfect intensive care unit room design. Infect Control Hosp Epidemiol. 2009;30:25-33. http://dx.doi.org/10.1086/592700

Address for correspondence: Catherine Neuwirth, Bacteriology

Department, University Hospital François Mitterrand, PTB, BP 37013,

21070 Dijon CEDEX, France; email: catherine.neuwirth@chu-dijon.fr 